\title{
A Novel Framework of an Expert System by integrating Capability Approach and BRB to Evaluate E-Government Services
}

\author{
Karl ANDERSSON ${ }^{1}$, Md. Shahadat HOSSAIN ${ }^{2}$, Devinder THAPA ${ }^{3}$, Pär-Ola ZANDER ${ }^{4}$ \\ ${ }^{1}$ Luleå University of Technology, Pervasive and Mobile Computing Laboratory, \\ SE-931 87 Skellefteå, Sweden, Tel: +46910 585300,Email: karl.andersson@ltu.se \\ ${ }^{2}$ Department of Computer Science and Engineering, University of Chittagong, \\ Chittagong 4331, Bangladesh, Tel: +88 031637971,Email: hossain_ms@cu.ac.bd \\ ${ }^{3}$ University of Agder, Department of Information Systems, P.O. Box 422, \\ NO-4604 Kristiansand, Norway, Tel: +47 381414 19, Email: devinder.thapa@uia.no \\ ${ }^{4}$ Department of Communication and Psychology, Aalborg University, Nyhavnsgade 14, \\ DK-9000 Aalborg, Denmark, Tel: +45 9940 3133,Email: poz@hum.aau.dk
}

\begin{abstract}
Capability approach is hard to operationalize and capabilities are sometimes difficult to reduce into the individual level. We describe our approach to solve these problems paired with an adequate ICT infrastructure and believe that the impact of concrete eGovernment services will become more visible and available. Citizens can inspect it, professionals can target their re-engineering on failure cases, learn from best cases, and researchers can compare different types of eGovernment. The solving of operationalisation will also strengthen the capability approach, by extending its scope from macro theory towards more easy application on the institutional and organizational levels.
\end{abstract}

\section{Introduction}

It is generally agreed that eGovernment has the potential to provide more efficient government, better services to citizens, and improve democratic process [1]. The proliferation of affordable technologies has also enhanced the possibility of technology diffusion in these areas. The application of eGovernment services can be equally beneficial to both developed and developing countries. For example, Estonia has shown that egovernment can succeed [2], also outside top $40 \mathrm{GDP} /$ capita countries, likewise there are many successes reported from developing countries as well [3]. However, despite large investments in eGovernment services, the long term impact is mostly unidentified. Little knowledge exists on the impact and results associated with e-government services in many specific use domains, and the failure risk remains high [4]. One of the main reasons behind this is the lack of systematic research and a holistic framework. Since development of eGovernment is a continuous process of improvement [5], it requires iterative evaluation of the overall e-government system (which is the combination of various e services) and its various dimensions such as determinants, characteristics and results [6]. Furthermore, eGovernment development is often complex because of multiple stakeholders, large user bases and complex goals. Consequently, even experts have difficulties in evaluating these systems, especially in an integrated and comprehensive way as well as on an aggregate level [7]. To get a holistic understanding of these complex systems, we need to identify various a posteriori capabilities, not a priori capabilities at the process level or implementation level of an eGovernment service while conversion factors in its outcome level. Conversion factors such as personal, social, political, and environmental are obstacles that hinder execution of acquired capabilities. The reason for considering a posteriori 
capabilities is that it allows the reasoning from known facts or past events rather than by making assumptions or predictions, which is the case with a priori. The assessment and evaluation of an eGovernment service should need to be carried out at these two levels by incorporating these capabilities and conversion factors. However, the accurate measurement of these capabilities and factors is difficult to achieve because they are subjective in nature and hence contains various types of uncertainty such as vagueness, inconsistently or in other ways they are challenging to formalize [7][8]. Therefore, it requires a novel framework which will allow the integration of a posteriori capabilities at implementation level and conversion factors at outcome level of an eGovernment service with a method that will facilitate its assessment and evaluation under uncertainty.

\subsection{Key research issues in identifying a posteriori capabilities at implementation and conversion factors at outcome levels of eGovernment services}

This multilevel assessment and evaluation also leads to theoretical and methodological challenges. For example, the theories that focused on equal distribution of resources or average happiness either focused on means or ends [9], whereas, to understand the holistic impact of eGovernment services we need a complete account of both means and ends. Likewise, lopsided use of qualitative or quantitative methodologies does not reveal the overall picture of eGovernment implementation process and outcome. To contribute to this problem area, AmartyaSen's [9] Capability Approach (CA) would be adopted. The reason for this is that CA does not focus on means (i.e. resources) but how these means can be instrumental to build human capabilities so that they can exercise their freedom of choice to live the life which they value, and have reason to value. Furthermore, CA is a holistic framework to understand the process of implementation and outcome of eGovernment service [10]. The CA suggests that impact evaluation should focus on the influence on people's capabilities to do and to be, on the quality of human life, and on the potential decrease in the obstacles in people's lives, to maximize everyone's freedom to live and choose the kind of life that they have reason to value [9]. Therefore, the CA places the emphasis on the contribution that eGovernment should have to make proper arrangements to deal with the conversion factors, such as political, social, personal and environmental challenges, at the same time, increase the capabilities (freedoms and opportunities) of individuals to function in their societies [11]. On the macro level, the HDI (Human Development Index) is derived from Sen's work [12]. On Micro level, there are also examples of impact evaluations [13][14].

However, most of the existing research [13][11][10][15] has used the CA as theoretical framework, but actual operationalization is missing. The operationalization in this context consists of 1) identification of a list of individual capabilities, 2) understanding the capability building process, and 3) evaluation of the achieved functioning (outcome when capabilities are executed). One of the good examples of operationalization of Capability Approach is as given in [14]. In case of eGovernment examples of individual capabilities at the implementation process are arrangement of political (democracy), social (participation), legal(justice) and environmental freedom while at the evaluation level are online participation, accessibility to governmental services, service delivery, improved interaction between G2C, increased transparency, etc. However, Klein [14] has also mentioned challenges in regard to identifying capabilities at implementation level and in evaluating them when they are executed or operationalize or are in functioning in the real world context. The challenge in case of eGovernment in identifying capabilities at implementation level would be different perception of users about eGovernment capabilities, ranking various capabilities, difficult to measure capabilities such as transparency, democracy, and requirements of multiple instruments to assess and evaluate the outcome. As mentioned 
earlier, using a priori list of capabilities does not fit in different contexts. It is not fit in the context of eGovernment because different countries have different socio-political model, likewise, complex configuration of eGovernment infrastructures. The other challenges are power manipulation, security issues, corruption, complex infrastructure, lack of skill (particularly in the context of developing countries). Sen also disagree with the idea of listing a priori capabilities [16]. Therefore, evaluation of a posterior capabilities is important to get the actual picture of impact of eGovernment services. Examples of a posterior capabilities in case of eGovernment at the implementation and at the outcome level are as mentioned earlier arrangement of political (democracy), social (participation), legal (justice) and environmental freedom, online participation, accessibility to governmental services, service delivery, improved interaction between G2C, increased transparency, etc. CA is useful in identifying a posterior capabilities, however to measure these capabilities it needs to complement with other frameworks such as statistical tools, fuzzy systems, and expert systems. The reason for this is that a posterior capabilities cannot be measured with $100 \%$ certainty. Existing studies have also suggested complementing CA with other theories, models or frameworks [17].

\subsection{Key research issues in framing a framework to assess and evaluate eGovernment Services under uncertainty}

Studies show that it is always a challenge to assess individual capabilities, because especially in the context of certain communities we need to look into collective capabilities rather than individual [18]. We argued that CA is useful to understand the capability building process by identifying the capabilities, however to evaluate an eGovernment service we need another framework, enabling us to carrying out the analytical analysis both at implementation and outcome levels. Therefore, we have proposed an integrated model of CA with Belief Rule Based Expert System (BRBES). The BRBES suggested by Hossain et al. [7] has been designed to evaluate the overall performance of an eGovernment system under uncertainty. It is interesting to note that a posteriori capabilities mentioned earlier are subjective in nature and hence it is difficult to measure them with $100 \%$ certainty. BRBES [7] is capable of handling uncertainty that exists with subjective data. This BRBES considers three categories of parameters such as determinants, characteristics, and results that are relevant to this study. The determinants, considered, consists of quality of the information and existing data to feed into the systems, technological infrastructure and compatibility, organisational and management-related characteristics, existing legal and institutional frameworks and potential demand. The characteristics consist of usability, quality of information available on web sites and in systems, privacy, security, interaction, integration, personalization, accessibility, and services. The results consists of statistics on systems usage, quality of public services, efficiency and productivity, effectiveness of programs and policies, transparency and accountability, citizen participation and changes in the regulatory framework. Most of these variables will be considered as initial points of empirical investigation, in order to find a posteriori capabilities that can be considered outcomes of an eGovernment service.

However, the limitations of this BRBES is that the above variables, related to the three categories, are a priori in nature i.e. context independent, whereas, the capabilities both at implementation and outcome levels are context dependent i.e. a posteriori in nature. The a posteriori capabilities at outcome level can be defined as their functioning ability when they are executed. This functioning ability may hinder by the conversion factors i.e. by the problems and challenges. In addition, this BRBES has not been designed to evaluate an eGovernment service both at implementation and outcome levels. Therefore, the knowledge base as well as the inference engine of this BRBES should need to be redesigned to cope 
with the a posteriori nature of eGovernment data. In addition, two tier BRBES architecture should be developed to handle knowledge and inference processing at both implementation and outcome levels. Therefore, we see that CA and BRB can play complementary roles in this context.

\section{Objectives}

In the research we are targeting, we have formulated two research questions.

1) How to identify various a posteriori individual capabilities developed by eGovernment services?

2) How to formulate a novel Belief Rule Based Expert System framework by incorporating Capability Approach to support a posteriori assessment and evaluation of eGovernment services both at implementation and outcome levels?

\section{Methodology}

To answer these research questions, we apply a mixed method approach. We conduct qualitative case study to identify the various capabilities that the eGovernment services can build and conversion factors (Problems and Challenges) that may hinder the capabilities building process. Thereafter, prioritize the identified list of capabilities and conversion factors both at implementation/process and outcome levels respectively; which is considered in framing a framework for a novel belief rule based expert system (BRBES). The BRBES is applied to evaluate eGovernment services at implementation level as well as at outcome level. It will also be applied to evaluate overall performance of eGovernment services in the light of the a posterior capabilities and conversion factors. This facilitates the generation of "what if" scenarios and hence, the identification of the conversion factors which are hindering the progress of eGovernment services. Eventually, the policy makers are able to take appropriate decisions to remove the bottlenecks. Therefore, our work makes a significant contribution by investigating a framework that combines CA and BRB to better understand the process of capability building process through eGovernment services, and its long-term impact on human development.

Capability approach has been applied in information and communication technologies for development (ICT4D) studies to explore the link between ICT and development [11][14][18]. One of the reasons for adoption of CA in these studies is its human orientated approach. Recent discourses in academia and practice have suggested that the objective of eGovernment should be also to enhance human capabilities [4][19]. In doing so, CA can be a relevant guide to the analysis of eGovernment impact on developmental process. Existing studies on eGovernment by applying CA framework advocate that it provides a holistic understanding of eGovernment services implementation and its impact on building human capabilities. In the following case study, researcher found that simple eGoverment services like pay-bill systems can improve the functioning of rural communities in paying their bills, which in turns can build capabilities such as empowerment and transparency [13]. In the context of developing countries, eGovernment service such as land record information systems is a huge problem to deal with [20]. In a similar case study, related to the land record information system of an Indian village, De [10] identified that a land record system accounted as successful, was in reality not able to build any capabilities. He found that while defining capabilities people participation was negligible, most of the capabilities listed were a priori. As a result, there villagers cannot exercise their capabilities even the system was successfully installed. Despite the huge potential of CA in impact evaluation, it is not without caveat. Kleine [14] has mentioned various challenges in the operationalization of CA framework. For example, identifying capabilities, prioritizing capabilities, differentiating between capabilities and functioning, and evaluation of 
achieved functioning need to be addressed. Suggestions are made to complement CA with other framework such as MDG [19], social capital [18] and expert systems [21].

From the positive aspects, CA can provide a better understanding of the implementation process and also helps in identifying capabilities. There is a lack of quantitative impact evaluation, for instance further investigation can be done to identify the impact of eGovernemnt services on human capabilities. For this purpose, we propose to combine CA framework with BRB expert systems, so that we get a holistic understanding of eGovernment implementation process and its impact on people's well-being.

Since the development of e-government is a continuous process, projects needs continuous assessment of its nascent stage or the transactional stages, in order to achieve its aims and for the stakeholders to take appropriate decisions [5][22]. However, present ways to evaluate e-government fail to take various forms of imprecision and complexity into account. For example, LRF [5] approach would allow the evaluators to perceive how the results are produced and to identify the contributing role of each variable in the overall evaluation of the eGovernment in an integrated way. However, the approach lacks the capability to address imprecision and complexity of an eGovernment project. Other approaches [23][24][25][26][27][28] do not allow such evaluation.

Since eGovernment evaluation is a complex issue, algorithmic solutions cannot be considered. A problem of this nature is often handled by developing an expert system. Expert systems have already shown their applicability within important fields of eGovernment evaluation [29][30][31]. However, they are not equipped to handle various types of uncertainties that exist with capabilities and conversion factors of eGovernment services and hence, the evaluation of an eGovernment service by these systems lacks the accuracy and the reliability [7]. A belief rule based expert system to evaluate an eGovernment service developed by Hossain et al. [7] demonstrated the ability to handle various types of uncertainties. The system uses Belief Rule Base as a knowledge representation schema which is capable of capturing the types of uncertainties that exist with the implementation and outcome levels' a posteriori capabilities and conversion factors of an eGovernment service. The Evidential Reasoning approach [32][33][34] has been used by the system to enable inferencing, which deals with multiple attribute decision analysis (MADA) of problems with both qualitative and quantitative attributes under uncertainties and hence, facilitates the handling of uncertainty in the inference process. BRB is the extended form of traditional IF-Then rule bases, and contains appropriate schemas to capture different types of uncertainties and allows the handling of non-linear causal relationships. Other Knowledge representation schemas such as Propositional Logic, First order logic is equipped to handle assertive knowledge. On the other hand, although FL handles some uncertainties due to ambiguity, vagueness or imprecision, it cannot handle other types of uncertainties such as ignorance, incompleteness, and ignorance in fuzziness, which may exist within the different categories of a posterior capabilities and conversion factors associated with e-government services. Case-Based Reasoning (CBR) is also used as a method to build a knowledge base [35][36]; however it accepts anecdotal evidence as its main operating principle and hence, the deduction of inference based on CBR is unreliable. In contrast, for a number of reasons, rule bases appear to be one of the most common forms for expressing various types of knowledge [37][38].As such, rule based expert systems usually constructed from human knowledge in the form of IF-Then rules become the most visible and fastest growing branch of Artificial Intelligence [37][38]. The capturing of human knowledge is essential to enabling the evaluation of e-government services and hence, building a knowledge base by using a belief rule base should be appropriate than that of CBR. Knowledge base building by the use of a rule base is also common in other areas of a problem domain, such as agricultural ecosystem management [39]. However, there remains some challenging research issues before adopting the belief 
rule based expert system to evaluate eGovernment developed by Hossain et al. [7] because this system has been developed to handle a priori knowledge not for a posteriori knowledge.

\section{Technology Description}

Our work develops a novel framework for a belief rule based expert system by integrating Capability Approach (CA) and Belief Rule Based inferencing using Evidential Reasoning (RIMER) to evaluate various eGovernment services. We are conducting qualitative case study of eGovernment services in Bangladesh and Sweden to identify the a posteriori capabilities as well as to identify the conversion factors (Problems and Challenges) that may hinder the capabilities building process at process/implementation and outcome levels. Furthermore, we develop two Belief Rule-Based sub-systems (IL-BRB and OL-BRB) for systematically evaluating eGovernment services at both Implementation Level (IL) and Outcome Level (OL). We are integrating the IL-BRB and the OL-BRB sub-systems into a single BRB system for evaluating eGovernment services under uncertainty. The technology developed will be evaluated in using cases related to eGovernment services of Bangladesh, Sweden, and Denmark.

\section{Developments}

\subsection{Empirical Study and Identification of Capabilities}

The Sen's CA framework applied to identify various capabilities generated through the eGovernment services. CA makes a distinction between means, such as eGoverrnment services, on the one hand, and functioning ends, such as education, healthcare, and good governance, and capabilities (freedoms and opportunities to achieve functioning), on the other. The basic importance of eGovernment services is that these are required to enable people to exercise their capabilities. Goods and services do not merely mean those things that are exchangeable for income or money, but the characteristics of such goods and services that interest people. For example, setting up educational systems in a village does not make a difference if it cannot provide localized content to the local community. Three groups of conversion factors-personal, social, and environmental-influence the relationship between commodities (goods and services) and the functioning to achieve certain beings and doings [9]. Personal conversion factors denote personal characteristics, such as the physical condition, sex, reading skills, and intelligence to convert commodities into a functioning. For example, an illiterate user cannot use a text-based user interface [40]. Social conversion factors are features such as social norms, public policies, gender roles, caste systems, and power relations. For example, the priorities of the dominant caste groups may determine the information systems' design and implementation, which could lead to the exclusion of marginal and non-dominant castes [41]. Likewise, an environmental conversion factor means the geographical location, climate, and infrastructure. The achieved functioning is a combination of the means through which to achieve them, the freedom to achieve them, and the personal preferences and social influences regarding the decision-making mechanisms [9]. A posteriori list of capabilities and conversion factors in existing researches have been identified. For this purpose, we conducted qualitative case studies using Sen's [9] capability approach as a guiding framework in Sweden, Denmark, and Bangladesh. The studies have been carried out without introducing the researcher's personal influence into the interpretations of the subject. The merit of this approach is that the researcher is well informed about the contextual setup, but does not have a direct personal stake in various interpretations and outcomes. The main data collection techniques in this case study adopted was in-depth interviews. Through this method, it is possible to access and assess the interpretations that actors have regarding the capabilities generated 
through eGovernment services and its consequence on development. It is also possible to observe the individual circumstances so that the researcher can use appropriate approaches, such as note-taking or tape-recording during interviews, to capture people's interpretations effectively. A data analysis phase followed the data collection. This study applied open coding scheme as suggested by Strauss and Corbin [42]. Collected qualitative data analyzed in line with existing studies [43][44]. The different case countries used to check that the project reached the stage of theoretical satiation [42]. A standard software tool, nVivo deployed to analyze the qualitative data that were observed and collected through qualitative case studies. These standard techniques can enhance the legibility and reliability of data during interpretive reporting. Nonetheless, qualitative research is not without constraints, for example, contrary to positivist studies, it is difficult to frame an objective or factual accounts of events and situations. It is more on seeking relativistic understanding of phenomena. Therefore, in this research the intent is to understand the deeper structure of a phenomenon rather than generalization from case studies to a population. The outcome of this research is a model in tree form (in the system to build). One tier of the model will be generic to all e-government services to be evaluated. Each capability will be described in terms of to what degree it is context-dependent with regards to national, organisational, and e-service context. Furthermore, we will theorize to what extent service-specific capabilities can appear in the case of particular eGovernment services, and the requirements of the BRB system with regards to that.

\subsection{Develop novel belief rule-based subsystems to evaluate eGovernment Services}

The assessment and evaluation of eGovernment services either at implementation level (IL) or at outcome level (OL) depend on multiple capabilities and conversion factors. The evaluation of an eGovernment service at implementation level is to be carried out by aggregating the a posteriori capabilities while at outcome level by aggregating conversion factors.

Therefore, a BRB tree, where the root node will be considered as the evaluation of an eGovernment service at implementation level developed. The main research point at this point consists of how to generate a framework in which the functional or logical relationships among the capabilities can explicitly be represented. This provided a basis for the development of a Belief Rule Based (IL-BRB) sub-system for evaluating an eGovernment service by measuring each capability at the bottom level of the tree and by aggregating them to obtain an overall performance of the eGovernment service by using for example evidential reasoning.

A number of situations need to be considered. For example, various types of uncertainties exist with the a posteriori capabilities and conversion factors mentioned previously. The accurate identification of the different types of uncertainties associated with each capability is necessary. Therefore, the operational definition of each capability in the context of case studies determined, facilitating the determination of different types of associated uncertainties. The main research point addressed here is how to identify the types of uncertainties associated with each capability. The construction of initial rule bases for IL-BRB, which requires the identification of the evaluation grade for the antecedent and consequent attributes of a rule has been performed. The bottom level or the leaf nodes of a tree can be considered as the antecedent attributes while the root level or the top level node can be considered as the consequent attribute. The overall performance of an eGovernment service at implementation level can be considered as the consequent attribute while various a posteriori capabilities can be considered as the antecedent attributes. In a BRB, a belief degree is considered with each evaluation grade of the consequent attribute. The challenges in developing belief rules include how these evaluation grades are defined quantitatively or qualitatively in logical and meaningful ways and how the belief degrees in the consequent 
of each rule are generated as consistently and accurately as possible. Figure 1 illustrates the interface of the IL-BRB expert system, where various a posteriori capabilities considered.

The research considered a number of ways to develop the initial rule base, 1) extracting belief rules from expert knowledge, 2) extracting belief rules from the examination of historical data, 3) using the previous rule bases if available, and by 4) using random rules without any pre-knowledge.

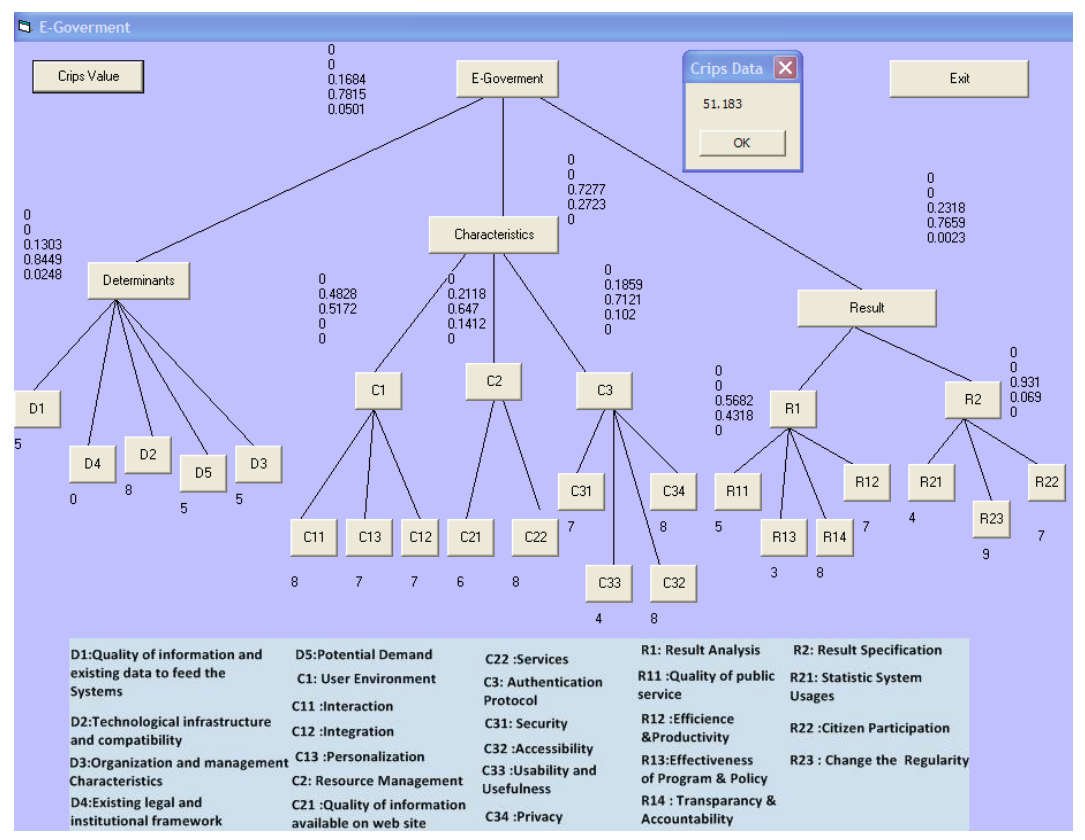

Figure 1: IL_BRB Expert System Interface

Further, the functional relationships among quantitative attributes used to develop belief rules which can approximate nonlinear functions, either continuous or discrete or both. For qualitative attributes, however, expert judgments have to be used. If subjective judgments are generated by a group of experts, belief degrees in a rule may not be added to one and may even need to be represented as interval values with or without distributions. More generally, subsets of consequent terms may be assigned degrees of belief rather than always singleton terms. Such rule based judgments are natural and common but very difficult to aggregate with rigor.

As mentioned previously the evaluation of an eGovernment service is a continuous and iterative process; and its evaluation need to be carried out at two levels namely at implementation and outcome levels. The IL-BRB developed procedures have already been described and hence, following the same, the OL-BRB developed. Therefore, a BRB tree to evaluate an eGovernment service at outcome level developed. Having developed the two subsystems (IL-BRB and OL-BRB), it is natural to undertake the task of integrating these subsystems into a single BRB system to support evaluation of eGovernment services in various environments using domain specific knowledge and data. There will be a need to once again fine tune the system by adjusting its overall structure and also training the parameters using overall input-output data or judgmental information. The challenge is how to calibrate the evaluation grades or values as well as belief degrees used for evaluating eGovernment services. However, accurate evaluation will also require the fine tuning of the system structure and its constituent parameters. So, a new optimization model and algorithm to train the integrated and enlarged BRB system is to be developed. The challenges of the training will be not only that optimal fitting to input-output data needs to be achieved but also that both the consistency and redundancy of the rules must be checked 
in order to avoid generating irrational or unreliable evaluation. Also, domain specific knowledge will need to be used for the training.

The novel belief rule based expert system will be validated by using various eGovernment services in Bangladesh, Denmark and Sweden.

\section{Results and Discussion}

While analyzing qualitative data we are heavily dependent on researcher's experiences and interpretations and hence, more prone to researcher biasness. To marginalize this error, we will conduct regular follow-up interviews with the interviewees and also evaluate the report through number of peer-reviews. Furthermore, to validate the methodological approach, we will apply the principles of hermeneutic circle [45]. The principles are also useful for addressing criteria such as authenticity, plausibility, and criticality [46]. For example, to ensure authenticity we will conduct our research in different countries, we will also conduct several rounds of interviews with various stakeholders who were directly or indirectly related to the eGovernment services; likewise, to ensure plausibility, we will present and discuss project results at various workshops and conferences. Finally, to ensure criticality we will discuss reports from different perspectives that will be useful for supporting or contradicting the interpretation and evaluation of the findings. Additionally, this will be focused on disseminating the results of the projects to high-level journals and conferences.

The BRB approach is promising, but it is not yet established how stakeholders receive the aggregation of detailed capabilities [7]. Will they learn from the BRB results? Will they try to renegotiate the weighting of the different BRB nodes? Will they resist the consequences? The outcome will document the user perception of the BRB system output. Another important outcome of the application will be to build an empirically based business understanding of the evaluation, notably how costly it is to apply an evaluation framework such as this one, and the evaluation culture of the eGovernment services in the applications above.

Our work has challenging research issues, such as identification of actual capabilities because of user perceptions influenced by various social, political, and cultural contexts, prioritization of identified capabilities, and generalization of capabilities. By developing a single and enlarge belief rule based expert system as well as its optimization model would facilitate the evaluation of eGovernment services under vague and incomplete information.

\section{Business Benefits}

As such, this research enriches decision theory, system theory, and decision support systems by providing a family of novel models and algorithms that are capable of processing precise, incomplete and vague information in a range of decision situations. It is believed that the research will stimulate more research in the area of decision analysis under uncertainty. Due to the nature of this research, the immediate beneficiaries will be academics, researchers, practitioners, eGovernment stakeholders and students interested in decision modeling and analysis, optimization, knowledge-based systems, and computing. The novel belief rule based system will provide a tool to support eGovernment service analysis by researchers, consultants, and many others. Our work is indeed expected to have a high significance and usefulness to the three research groups involved in Sweden, Bangladesh and Denmark. This particular research is directed towards applications in the area of a belief-rule-based expert system to evaluate eGovernment services but the collaboration can later on easily be extended to innovative use of ICT-based tools in e.g. distance-spanning engineering work, e-health, ICT-supported elderly care, digital education, etc. 


\section{Conclusions}

The research presented in this paper mainly consists of investigating a novel framework to evaluate e-Government services. It has been demonstrated that an integration of Capability Approach with Belief Rule Based system is required to achieve this. The Capability Approach can be used to identify various a posteriori factors both at implementation level and outcome level. However, it is important to identify the various types of uncertainty that exist with the both levels. Finally, since the evaluation of eGovernment services is a complex process and it consists of various types of uncertainty, a belief rule based expert system can be developed to obtain the overall picture of the services at an aggregated level. However, in this research two-tier belief rule based one is at implementation level and the other being at outcome level have been considered. The integrations of these BRB systems are necessary to get the overall picture of eGovernment service, which will be performed as part of the later research. By using the expert system various types of scenarios can be generated which will eventually help to develop various policies to have an effective eGovernment Service, especially at micro level. This research also demonstrated a way how the CA can be operationalized at individual level.

\section{References}

[1] Grönlund, Å. and Horan, T. A. (2005). Introducing e-gov: history, definitions, and issues. Communications of the Association for Information Systems, 15(1), 39.

[2] Kalvet, T. (2012). Innovation: a factor explaining e-government success in Estonia. Electronic Government, An International Journal, 9(2), 142-157

[3] Oh, M. and Larson, J. F. (2013). Digital development in Korea: building an information society. New York: Routledge.

[4] Heeks, Richard (2003). Most egovernment-for-development projects fail: how can risks be reduced?. Manchester: Institute for Development Policy and Management, University of Manchester, 2003.

[5] Al-Sebie, M., and Irani, Z. (2005). Technical and organisational challenges facing transactional egovernment systems: an empirical study. Electronic Government, an International Journal, 2(3), 247- 27

[6] Luna-Reyes, L. F., Gil-Garcia, J. R., and Romero, G. (2012). Towards a multidimensional model for evaluating electronic government: Proposing a more comprehensive and integrative perspective. Government Information Quarterly, 29(3), 324-334. doi:10.1016/j.giq.2012.03.001

[7] Hossain, M.S., Zander, P.O., Kamal, S. and Chowdhury, L., (in press) A Belief Rule Based Expert System to Evaluate E-Government. Accepted for publication in the Expert Systems: The Journal of Knowledge Engineering, Jhon Wiley \& Sons Ltd.,

[8] Hossain, M.S., Zander, P.O., and Jonasen, T.S., (2014) An Evaluation of the State of Local eGovernance in Bangladesh. Proceedings of the International IFIP Electronic Government (EGOV) Conference 2014, Trinity College, Dublin, Ireland, 1-4th September, 2014.

[9] Sen, A. (1999). Development as freedom. Oxford University Press.

[10] De, R. (2006) Evaluation of e-government systems: project assessment vs development assessment, In Wimmer, M.A., Scholl, H.J., Grönlund, A. and Andersen, K.V. (Eds.): Electronic Government 5th International Conference, EGOV 2006, Springer-Verlag, September, pp.317-328.

[11] Zheng, Y. (2009). Different spaces for e-development: What can we learn from the capability approach? Information Technology for Development, 15(2), 66-82.

[12] Haq, M. ul. (1995). Reflections on human development. New York: Oxford University Press

[13] Madon, S. (2004) 'Evaluating the developmental impact of e-governance initiatives: an exploratory framework', Electronic Journal of Information Systems in Developing Countries, Vol. 20, No. 5, pp.113.

[14] Kleine, D. (2010). ICT4WHAT?-Using the choice framework to operationalise the capability approach to development. Journal of International Development,22(5), 674-692.

[15] Stillman, L. and Denison, T. (2014). The Capability Approach Community Informatics. The Information Society, 30(3), 200-211. http://doi.org/10.1080/01972243.2014.896687

[16] Robeyns, I. (2005). The capability approach: a theoretical survey. Journal of human development, 6(1), 93-117.

[17] Clark, D. A. (2005). The Capability Approach: Its Development, Critiques and Recent Advances. 
[18] Thapa, D., Sein, M. K., and Sæbø, Ø. (2012). Building collective capabilities through ICT in a mountain region of Nepal: where social capital leads to collective action. Information Technology for Development, 18(1), 5-22.

[19] Bhatnagar, S. (2004) E-government. From Vision to Implementation: A Practical Guide with Case Studies, Sage Publications, India.

[20] Furuholt, B., Wahid, F., and Sæbø, Ø. (2015). Land Information Systems for Development (LIS4D): A Neglected Area within ICT4D Research? HICSS conference proceedings.

[21] Chiappero-Martinetti, E., Egdell, V., Hollywood, E., and McQuaid, R. (2015). Operationalization of the capability approach. In Facing Trajectories from School to Work (pp. 115-139). Springer International Publishing.

[22] Gupta, M. P. and Jana, D. (2003). E-government evaluation: a framework and case study. Government nformation Quarterly, 20(4), 365-387

[23] Dawes, S. S. (2008). The evolution and continuing challenges of e-governance. Public Administration Review, 68(s1), S86-S102.

[24] Esteves, J. and Joseph, R. C. (2008). A comprehensive framework for the assessment of eGovernment projects. Government Information Quarterly, 25(1), 118-132. doi:10.1016/j.giq.2007.04.009

[25] Karunasena, K. and Deng, H. (2012). Critical factors for evaluating the public value of e-government in Sri Lanka. Government Information Quarterly, 29(1), 76-84. doi:10.1016/j.giq.2011.04.005

[26] Raus, M., Liu, J. and Kipp, A. (2010). Evaluating IT innovations in a business-to-government context: A framework and its applications. Government Information Quarterly, 27(2), 122-133. doi:10.1016/j.giq.2009.04.007

[27] Stowers, G. N. (2004). Measuring the performance of e-government. In e-Government series (p. 52).Washington, DC: The Center for the Business of Government

[28] Verdegem, P. and Verleye, G. (2009). User-centered E-Government in practice: A comprehensive model for measuring user satisfaction. Government Information Quarterly, 26(3), 487-497. doi:10.1016/j.giq.2009.03.005

[29] Magoutas, B. and Mentzas, G. (2010). SALT: A semantic adaptive framework for monitoring citizen satisfaction from e-government services. Expert Systems with Applications, 37(6), 4292-4300. doi:10.1016/j.eswa.2009.11.071

[30] Shan, X., Xin, T., Wang, L., Li, Y., and Li, L. (2013). Identifying Influential Factors of Knowledge Sharing in Emergency Events: A Virtual Community Perspective. Systems Research and Behavioral Science, 30, 367-382.

[31] ShefferCorrêa, A., de AssisMota, A., Toledo Moreira Mota, L., and Luiz Pizzigatti Corrêa, P. (2014). A fuzzy rule-based system to assess e-government technical interoperability maturity level. Transforming Government: People, Process and Policy, 8(3), 335-356. http://doi.org/10.1108/TG-08-2013-0028

[32] Hossain, M. S., Chowdhury, M. S. U., and Sarker, S. (2013). Intelligent Tender Evaluation System Using Evidential Reasoning Approach. International Journal of Computer Applications, New York, USA, 61(15), 38-43.

[33] Jian-Bo, Y. and Sen, P. (1997). Multiple Attribute Design Evaluation of Large Engineering Products Using The Evidential Reasoning Approach. Journal of Engineering Design, 8(3), 211-230.

[34] J. B. Yang and M. G. Singh. (1994). An evidential reasoning approach for multiple attribute decision making with uncertainty, IEEE Transactions on Systems, Man, and Cybernetics, Vol.24, No.1, pp.1-18, ISSN 0018-9472.

[35] Fang, S., Xu, L., Pei, H., Liu, Y., Liu, Z., Zhu, Y., and Zhang, H. (2014). An Integrated Approach to Snowmelt Flood Forecasting in Water Resource Management. IEEE Transactions on Industrial Informatics, 10(1), 548-558. doi:10.1109/TII.2013.2257807

[36] Sun, B., Xu, L., Pei, X., and Li, H. (2003). Scenario-based knowledge representation in case-based reasoning systems. Expert Systems, 20(2), 92-99. doi:10.1111/1468-0394.00230

[37] Jian-Bo Yang, Jun Liu, Jin Wang, How-Sing Sii, and Hong-Wei Wang. (2006). Belief rule-base inference methodology using the evidential reasoning Approach-RIMER. IEEE Transactions on Systems, Man, and Cybernetics - Part A: Systems and Humans, 36(2), 266-285. doi:10.1109/TSMCA.2005.851270

[38] Sun, R. (1995). Robust reasoning: integrating rule-based and similarity-based reasoning. Artificial Intelligence, 75(2), 241-295. doi:10.1016/0004-3702(94)00028-Y

[39] Xu, L., Liang, N., and Gao, Q. (2008). An Integrated Approach for Agricultural Ecosystem Management. IEEE Transactions on Systems, Man, and Cybernetics, Part C (Applications and Reviews), 38(4), 590-599. doi:10.1109/TSMCC.2007.913894

[40] Medhi, I., Prasad, A., and Toyama, K. (2007). Optimal audio-visual representations for illiterate users of computers. In Proceedings of the 16th international conference on World Wide Web (pp. 873-882). ACM. 
[41] De, R. and Ratan, A. L. (2009). Whose gain is it anyway? Structurational perspectives on deploying ICTs for development in India's microfinance sector. Information Technology for Development, 15(4), 259-282.

[42] Strauss, A. and Corbin, J. M. (1990). Basics of qualitative research: Grounded theory procedures and techniques. Sage Publications, Inc.

[43] Andrade, A. D. (2009). Interpretive research aiming at theory building: Adopting and adapting the case study design. The Qualitative Report, 14(1), 42-60.

[44] Urquhart, C., Lehmann, H., and Myers, M. D. (2010). Putting the 'theory' back into grounded theory: guidelines for grounded theory studies in information systems. Information systems journal, 20(4), 357381.

[45] Klein, H. K. and Myers, M. D. (1999). A set of principles for conducting and evaluating interpretive field studies in information systems. MIS quarterly, 67-93.

[46] Walsham, G. (2006). Doing interpretive research. European journal of information systems, 15(3):320330. 